\title{
COMUNICAÇÕES
}

\section{UMA CONTRIBUIÇÃO AO APRIMORAMENTO DA INFORMAÇÃO CONTÁBIL, NO TOCANTE À MENSURAÇÃO DO RESULTADO CONTÁBIL DA PRODUTORA CINEMATOGRÁFICA}

\author{
Ricardo Lopes Cardoso \\ Doutorando em Controladoria e Contabilidade pela FEA-USP \\ Mestre em Ciências Contábeis pela FAF-UERJ \\ Professor Assistente da FAF-UERJ \\ E-mail: rlopesc@uerj.br
}

\author{
Natan Szuster \\ Professor Titular da Universidade Federal do Rio de Janeiro - UFRJ \\ Professor Adjunto da Universidade do Estado do Rio de Janeiro - UERJ \\ E-mail: szuster@iis.com.br
}

\section{RESUMO}

Este artigo apresenta uma proposta de aprimoramento dos critérios de mensuração do resultado contábil de uma produtora cinematográfica que realiza suas atividades no mercado brasileiro.

O interesse pelo assunto é motivado pela admiração ao cinema, em especial, o nacional.

A necessidade de aprimoramento da informação foi constatada pela falta de normas de procedimentos contábeis a serem observados pelas produtoras nacionais.

Neste trabalho foi desenvolvido um modelo contábil próprio considerando a produção de um filme como um contrato de longo prazo, sendo o resultado apurado de acordo com a geração efetiva de receitas.

Palavras-chave: contabilidade do cinema, produtora cinematográfica, ativos especiais, informação contábil, resultado contábil em atividades especiais.

\section{ABSTRACT}

This article presents a proposal to improve the criteria for measuring the accounting income of a movie producer active in the Brazilian market.

Our interest in this subject is motivated by our admiration for cinema, and particularly for national productions.

The need to improve information was observed as a result of the lack of standards for accounting procedures to be observed by the national producers.

In this study, we develop a particular accounting model considering the production of a movie as a long-term contract, while income is determined in accordance with the actual creation of revenues.

Keywords: movie accounting, movie producer, special assets, accounting information, accounting income in special activities. 


\section{INTRODUÇÃO}

Como metodologia da pesquisa, foram estudados os mecanismos de fomento disponibilizados no Brasil (pela União, pelo Governo do Estado do Rio de Janeiro e pela Prefeitura da cidade do Rio de Janeiro), pois o financiamento com recursos públicos é classificado pela maioria dos produtores como indispensável à manutenção e ao aumento da produção cinematográfica nacional.

Também foram estudados os critérios internacionais e nacionais de apuração do resultado contábil da produtora cinematográfica.

Dentre os internacionais, foram estudados aqueles preconizados do Financial Accounting Standards Board - FASB (SFAS 53 e SFAS 139) e um desenvolvido, para fins da Dissertação, consubstanciado nas normas emanadas pelo International Accounting Standards Board - IASB.

Quanto aos critérios nacionais, pôde-se concluir que no Brasil não há um legalmente estabelecido pelos órgãos reguladores. Essa constatação foi obtida em entrevistas com profissionais de diversas produtoras, buscando-se identificar como cada uma apura seu resultado e avalia o respectivo patrimônio. Em função da diversidade das características e de modelos levantados, fez-se a classificação das produtoras visitadas em três tipos: pequeno, médio e grande portes.

Por produtora de grande porte considerou-se aquela que é concessionária de serviços de radiodifusão e cabodifusão de sons ou imagens. Por produtora de pequeno porte considerou-se aquela de reduzida estrutura administrativa, isto é, que utiliza serviços terceirizados para desenvolver atividades administrativas e financeiras; enquanto que a produtora de médio porte conta com quadro de pessoal próprio para desenvolver as atividades administrativas e financeiras.

Como produto final deste trabalho, foi proposto um modelo próprio, que é apresentado neste artigo, o qual busca utilizar os melhores aspectos dos modelos nacionais e internacionais estudados. Este modelo objetiva aprimorar a capacidade informativa das Demonstrações Contábeis elaboradas pelas produtoras cinematográficas brasileiras, através da mensuração do resultado utilizando de forma plena os Princípios Contábeis.
Cabe ressaltar que as demonstrações contábeis exigidas pelo Ministério da Cultura (MinC) e demais órgãos de fomento não têm este objetivo, mas tão somente, averiguar se os recursos incentivados foram efetivamente aplicados na produção cinematográfica à qual foram destinados. O objetivo da Comissão de Valores Mobiliários (CVM), entidade reguladora que também exige Demonstrações Contábeis das produtoras brasileiras, consiste exclusivamente em apurar o valor das participações (ou dividendos) aos quais os portadores de Certificados de Investimentos no Audiovisual têm direito.

Após este trabalho espera-se que os agentes econômicos relacionados à produção de cinema no Brasil tenham maiores condições para uma gestão mais eficaz dos recursos aplicados na atividade.

\section{CARACTERÍSTICAS DA INDÚSTRIA}

Objetivando situar o leitor no tocante ao setor econômico estudado, considera-se indústria do audiovisual o conjunto de três entidades distintas, cujas atribuições são nitidamente definidas: a produtora, a distribuidora e a exibidora.

\section{Produtora}

A produtora é a entidade que realiza o filme. $\mathrm{O}$ ato de realizar o filme pode ser sintetizado em três etapas: a pré-produção, a produção e a pós-produção.

A pré-produção compreende a aquisição dos direitos sobre uma obra e a sua transformação em roteiro ou a aquisição dos direitos sobre um roteiro; a preparação do projeto orçamentário; a contratação de pessoal (diretores, atores, câmeras e pessoal de apoio) e a captação de recursos.

A produção, propriamente dita, envolve as atividades de filmagem, administração de pessoal e gestão dos recursos captados.

A pós-produção é relacionada com a finalização, edição e pós-edição do filme, abrangendo também atividades de administração de pessoal e de gestão dos recursos captados.

A comercialização do filme não foi relacionada acima, por tratar-se da principal função da distribuição, conforme será visto a seguir. 


\section{Distribuidora}

A distribuição compreende as atividades de divulgação do filme na mídia e a comercialização do mesmo com os veículos de exibição.

Muitas das vezes, o músico responsável pela triIha sonora, o fabricante de brinquedos com o tema de personagens do filme e outros licenciados impulsionam a divulgação do filme, mas não se confundem com a figura do distribuidor. Este "fecha o contrato" com o exibidor, entregando a película às salas de projeção onde o filme será exibido, por exemplo.

\section{Exibidora}

O exibidor é o veículo que coloca o filme à disposição do público. À primeira análise, pode-se associar a atividade de exibidor com as salas de projeção, entretanto, a exibição pode não ocorrer só no cinema, mas nas outras "janelas de exibição" como o home-video, a TV aberta, a TV fechada e o pay-per-view.

\section{Distribuição da receita entre as entidades}

Normalmente, a produtora contrata uma distribuidora para comercializar seus filmes.

Os direitos e deveres de cada parte (produtora e distribuidora) dependem do estipulado em cada contrato, mas podemos identificar, como sendo praxe do mercado, que a distribuidora assume a responsabilidade de comercializar determinado filme, com exclusividade, em um mercado específico, por exemplo, salas de cinema de determinada área geográfica do território brasileiro, durante um período de tempo limitado, e sua remuneração, normalmente, varia em função do sucesso do filme, que é mensurado pela receita auferida naquele mercado.
A rigor, o custo de divulgação é da produtora, mas esta não costuma ter recursos suficientes para divulgar seus filmes e, portanto, não é raro a distribuidora adiantar recursos ao produtor. Nessa transação, a distribuidora não entrega o dinheiro à produtora, simplesmente gasta em nome desta, e faz o controle dos valores em uma espécie de conta-corrente, os quais são compensados com os que a distribuidora tiver que repassar à produtora, referentes à receita do filme.

Vejamos um exemplo: A produtora YLC Filme Ltda. contrata com Naninha Distribuição de Filmes Ltda. a distribuição do filme Em Família.

Mediante o contrato de distribuição, ficou acordado que a distribuidora poderá comercializar o filme, somente em salas de exibição (cinema) do território nacional, fazendo juz a uma remuneração de $45 \%$ sobre o valor repassado pelo exibidor, deduzido do adiantamento para divulgação.

A distribuidora gasta, em nome da produtora, $\$ 20.000$ com a divulgação do filme no mercado nacional.

A distribuidora comercializa o filme com o Grupo RYC de Cinema S.A. (exibidor), que exige uma comissão de $40 \%$, calculada sobre o valor apurado na bilheteria, líquido de impostos, que correspondem a $5 \%$ da receita bruta.

Desta forma, o montante auferido na bilheteria é subtraído dos impostos, da comissão do exibidor, do gasto com divulgação realizado pela distribuidora, em nome da produtora, e da comissão da distribuidora, chegando-se, portanto, à receita bruta da produtora.

Considerando-se que em determinado período foram vendidos dez mil ingressos do filme Em Família, por \$10, cada, temos:

Tabela 1 - Demonstração da distribuição da receita

\begin{tabular}{lrll}
\hline itens & valor & entidade & observação \\
\hline Bilheteria (10.000 ingressos x \$10/ingresso) & 100.000 & & valor auferido na bilheteria \\
Impostos (5\%) & $\frac{(5.000)}{95.000}$ & & \\
Bilheteria líquida de impostos & $\underline{(38.000)}$ & Grupo RYC & receita do exibidor \\
Comissão exibidor (40\%) & $\frac{57.000}{}$ & & $\begin{array}{l}\text { valor repassado ao distribuidor } \\
\text { Bilheteria líq. de imp. e comis. do exibidor retido pelo distribuidor }\end{array}$ \\
Valor adiantado pelo distribuidor & $\underline{(20.000)}$ & & \\
Base de cálculo da comissão do distribuidor & $\frac{(16.000}{20.350)}$ & Naninha & receita do distribuidor \\
Comissão distribuidor (45\%) & YLC & valor repassado ao produtor \\
Bilheteria líquida de impostos e comissões & $\underline{\underline{20.350}}$ & &
\end{tabular}


Considerando que o valor adiantado pelo distribuidor para a comercialização do filme é uma despesa da produtora, esta deve reconhecer a receita no montante de $\$ 40.350$ e a despesa de comercialização no valor de $\$ 20.000$.

\section{PRINCIPAIS DIFERENÇAS ENTRE OS MODELOS INTERNACIONAIS}

Neste trabalho, são apresentadas, apenas, as principais diferenças entre o modelo preconizado pelo SFAS 139 e aquele elaborado mediante interpretação das normas do IASB. Desta forma, não é feita qualquer menção ao método estabelecido pelo SFAS 53 , tendo em vista que o mesmo não é mais observado pelas produtoras norte americanas desde a segunda quinzena de dezembro de 2000 , quando o SFAS 139 entrou em vigor.

Podemos concluir que, no tocante à mensuração do resultado contábil da produtora cinematográfica, o modelo gerado segundo as normas do IASB difere, em aspectos relevantes, do modelo preconizado pelos USGAAP.

Poder-se-ia afirmar que o modelo produzido conforme as normas do IASB é mais conservador que o estabelecido pelos USGAAP, não fosse o fato de o IASB permitir a amortização dos custos de produção em vinte anos e os USGAAP somente em dez anos. Afinal, o IASB não admite a capitalização dos gastos de pré-produção e só permite o reconhecimento dos recursos incentivados como receita à medida que a produtora for amortizando os gastos de produção. Considerando que a produtora realize um único filme, seu patrimônio estará mensurado diferentemente pelos dois métodos, pelo menos, até que o filme seja totalmente amortizado.

Em suma, as principais diferenças entre os dois modelos são:

a) o tratamento dado aos gastos de pré-produção, que pelo FASB compreendem os custos do filme e pelo IASB são contabilizados como despesas, assim que incorridos;

b) os USGAAP são taxativos quanto ao critério de amortização dos gastos de produção (individual-film-forecast-computation-method), enquanto o IASB permite que a amortização seja efetuada de diferentes formas desde que 0 critério adotado seja aplicado consistente e sistematicamente; c) os USGAAP consideram como vida útil do filme a receita que se espera auferir no período de dez anos a contar da estréia do mesmo; pelo IASB, este período é de vinte anos;

d) o reconhecimento, como receita, dos recursos incentivados, pelos USGAAP ocorre integralmente no instante em que a produtora não tiver mais qualquer obrigação para com o governo, relativa aos recursos captados, enquanto pelo IASB se processa paulatinamente, conforme a produtora for amortizando os gastos de produção do filme para o qual os recursos foram captados.

\section{COMPARAÇÃO DOS MODELOS NACIONAIS}

Os relatórios de prestação de contas que as produtoras apresentam aos órgãos de fomento não são abordados neste trabalho, pois, têm por escopo apenas demonstrar que os recursos captados foram efetivamente aplicados na produção do filme, na forma definida no projeto de produção aprovado pelo mesmo órgão e, portanto, não têm o objetivo de mensurar o desempenho da produtora. Nesse sentido, são comparados os modelos contábeis adotados pelos três tipos de produtoras nacionais entrevistadas (classificadas em pequeno, médio e grande portes).

O método adotado pela produtora de pequeno porte não considera o filme como um ativo, pois, produziu o filme com recursos captados. Todos os gastos de produção são considerados despesas no momento em que a produtora neles incorreu e os recursos incentivados são considerados receitas, pelo mesmo montante, no mesmo momento em que as despesas forem sendo contabilizadas, para que haja confrontação entre as despesas e as receitas.

O método adotado pela produtora de médio porte considera o filme como um ativo, entretanto, assim que finaliza a produção e obtém a aprovação do órgão de fomento em sua prestação de contas, faz o cotejamento do custo do filme com o montante de recursos captados, mantendo o filme contabilizado pela diferença, ou saldo remanescente. Esse saldo é amortizado à medida que a produtora vai auferindo receita com o filme, sendo o valor da amortização o mesmo da receita, até que reste um centavo como custo do filme. Esse valor simbólico é transferido de 
estoque (ativo circulante) para imobilizado (ativo permanente), onde permanece ad perpetum, sem ser amortizado nem depreciado.

As semelhanças entre os métodos adotados pelas empresas de pequeno porte e médio porte são, basicamente, que ambos tendem a reconhecer as receitas e as despesas pelo regime de caixa.

O método adotado pela empresa de grande porte é bastante diferente dos demais métodos nacionais, pelos seguintes motivos principais:

a) à produtora de grande porte é vedado captar recursos públicos mediante os mecanismos de fomento disponibilizados pela legislação brasileira e, conseqüentemente, não reconhece o passivo circulante (recursos incentivados), nem a receita incentivada;

b) a amortização dos gastos de produção é reconhecida, não só em função da receita auferida (tal como os modelos SFAS 53, SFAS 139 e IASB), mas, também, em função do mercado explorado, permitindo um controle gerencial do desempenho comercial da produtora/distribuidora, se as receitas forem razoavelmente projetadas.

A principal semelhança entre o modelo adotado pela empresa de grande porte, o modelo adotado pela empresa de médio porte e os modelos norte-americanos (SFAS 53 e SFAS 139) é o critério de capitalização dos gastos de produção, ou seja, os quatro modelos consideram os custos de pré-produção, produção e pós-produção como ativo da entidade produtora.

\section{APRESENTAÇÃO DO MODELO PROPOSTO}

Tendo-se concluído pela falta de um modelo padrão a ser adotado, no momento, pelas produtoras brasileiras, foi proposto um modelo, onde são aproveitados alguns critérios de cada um dos estudados, efetuando uma alteração básica, que consiste em reconhecer toda receita e despesa, sempre, pelo Princípio da Competência.

O aprimoramento é motivado pela necessidade de gerar relatórios com maior capacidade informativa, pois a falta de comparabilidade entre as demonstrações contábeis emitidas pelas diversas produtoras ocasiona o inevitável descontrole do desempe- nho de suas atividades e, conseqüentemente, seu desconhecimento por parte dos usuários das demonstrações contábeis, externos às produtoras.

Esse descontrole e desconhecimento têm como reflexo, imediato, dificultar o acesso das produtoras ao financiamento.

Afinal, os investidores privados não se motivam a financiar a indústria cinematográfica, pois desconhecem os riscos que correm ou, se optarem por financiar essa atividade, poderão exigir taxas de juros muito acima das praticadas pelo mercado, em função do prêmio pelo risco, inviabilizando o empreendimento.

\section{Capitalização dos gastos de produção}

Todos os custos incorridos nas três fases de produção (pré-produção, produção e pós-produção), inclusive os gastos com publicidade do filme, desde que o filme ainda não tenha sido lançado no mercado, devem ser contabilizados como ativo da produtora, avaliados pela identificação específica e mensurados em moeda constante, aproveitando o arcabouço teórico desenvolvido, no Brasil, com o instituto da Correção Monetária Integral, independentemente do nível de inflação.

Entendendo-se por custos de produção, tanto os diretos quanto os indiretos, desde que rastreáveis por bases racionais e consistentes de rateio.

Considerando o lapso temporal decorrido entre o início da fase de pré-produção e a data na qual a produtora começa a auferir receita de comercialização com o filme, podemos entender a produção cinematográfica como a elaboração de um ativo de longa maturação. Dessa forma, uma proposta é contabilizar os encargos financeiros efetivos como custos de produção, os quais devem ser capitalizados na mesma conta que registrar o estoque. Estes valores serão amortizados de acordo com a geração de receitas, não penalizando os períodos em que o filme estiver sendo produzido, ou seja, pelo mesmo critério dos demais custos de produção.

Um exemplo de gasto com publicidade que deve ser ativado é aquele relativo à elaboração do making-of, pois o mesmo não se exaure pelo fator tempo, já que tende a ser utilizado no processo de divulgação e promoção do filme em cada nova janela (i.e. mercado, canal de exibição) na qual o filme será comercializado. Portanto, o making-of 
tende a contribuir ao acréscimo da receita em todas as janelas de comercialização onde o filme for exibido.

Por outro lado, alguns gastos incorridos com a pós-produção e publicidade não devem ser contabilizados como custo de produção, como é o exemplo de dublagem e legendagem (pós-produção) e os gastos publicitários que visam mercados específicos. Ou seja, os gastos incorridos com pós-produção e/ou publicidade, quando não for esperado acréscimo na geração de receita de todas as janelas de comercialização, devem sem contabilizados no ativo, como despesa antecipada, e amortizados em função da receita ou do tempo esperado para que tais gastos gerem benefícios econômicos naquele mercado no qual foram incorridos.

Vale ressaltar que as demais despesas da produtora, como os valores gastos com publicidade institucional, por exemplo, devem ser reconhecidos contabilmente como despesa na data na qual a produtora nelas incorrer.

Objetivando identificar a qualidade do ativo da produtora, principalmente do estoque, sugere-se que os gastos incorridos na produção do filme, enquanto este não estiver pronto, devem ser evidenciados na conta "Estoque de projetos em andamento - filme xpto". Quando o filme estiver pronto para ser comercializado, a produtora deverá transferir o saldo de "Estoque de projetos em andamento - filme xpto" para a conta "estoque de filme - xpto".

Os filmes têm características de estoque. Entretanto não se trata de um estoque de bens tangíveis, mas de direitos. Daí porque se diz que os filmes são Ativos Especiais. Além disso, uma parte substancial de seus benefícios potenciais são gerados no curto prazo (ativo circulante, em função da receita normalmente auferida durante sua comercialização, a qual dificilmente perdura por mais de doze meses a contar da data de lançamento), e de longo prazo (ativo realizável a longo prazo, pois mesmo após o período normal de comercialização, isto é, anos após seu lançamento, a produtora pode negociar seus direitos de exibição novamente, por exemplo com canais abertos de televisão, auferindo novas receitas).

\section{Receita de comercialização}

O reconhecimento da receita de comercialização deve respeitar o Princípio da Competência.

Dessa forma, a receita fixa (auferida na negociação com um canal de tv aberta, por exemplo) deve ser reconhecida quando a produtora (ou distribuidora) assinar o contrato com o exibidor e transferir o direito de exibição, entregando-lhe a película. A receita variável (auferida mediante exibição em salas de cinema, por exemplo) deve ser reconhecida de forma simultânea à obtenção das informações sobre o seu montante, independentemente da data de recebimento. Conseqüentemente, a receita híbrida (auferida com a reprodução do filme em DVD e VHS, por exemplo, mediante a qual a produtora recebe um valor fixo pelo licenciamento e um percentual das vendas) deve ter a parcela fixa reconhecida na forma da receita fixa (quando da assinatura do contrato) e a parcela variável na da receita variável (quando o valor for conhecido).

\section{Recursos incentivados}

De forma geral, o procedimento adotado pelas produtoras para captar recursos públicos segue o seguinte fluxo:

Primeiro, a produtora apresenta seu projeto de produção de um determinado filme ao órgão de fomento, que o analisa e aprova, ou não. Sendo o projeto aprovado, é expedido, pelo órgão de fomento, uma autorização para a produtora captar recursos mediante o incentivo fiscal pleiteado.

De posse dessa autorização, o produtor entra em contato com contribuintes do tributo mediante o qual Ihe foi autorizado captar recursos, para oferecer-lhes a oportunidade de investir na produção cinematográfica nacional mediante determinado incentivo fiscal.

Se o contribuinte concordar em patrocinar o projeto, ele deverá depositar a respectiva quantia em uma conta corrente vinculada ao projeto, aberta para este fim, em nome da produtora e do fisco que concedeu o incentivo.

Embora o recurso já tenha sido depositado, a produtora não o deve reconhecer como ativo, pois o mesmo ainda não está à sua disposição, o que só ocorrerá quando a produtora obtiver, do poder público, uma autorização para movimentar os recursos captados.

Essa autorização costuma ser concedida logo após a produtora cumprir um rol de obrigações que abrange, entre outras exigências, prova de que ela e o contribuinte patrocinador estão em dia com suas obrigações fiscais. 
Obtendo a referida autorização e estando o numerário à disposição da entidade, os recursos incentivados devem ser reconhecidos no ativo circulante (conta vinculada) tendo como contra partida o passivo, que representa a obrigação de produzir o filme na forma definida no projeto anteriormente aprovado. Caso a produtora não finalize o filme, ou o faça de forma diferente da autorizada, estará sujeita a ter que restituir o valor captado com juros e multa, além de seu representante legal ficar sujeito a responder civil e criminalmente.

Se o prazo da produtora, para finalizar a obra e prestar contas aos órgãos de fomento, contado da obtenção do incentivo, vencer nos doze primeiros meses, os recursos captados deverão ser contabilizados no passivo circulante. Se o prazo previsto for superior aos doze primeiros meses, os recursos captados deverão ser contabilizados no exigível a longo prazo.

Conforme a produtora for incorrendo em gastos para realizar o filme, o saldo da conta vinculada vai sendo consumido e, analogamente, o valor do estoque de projeto em andamento vai aumentando, até que o filme seja finalizado, portanto, avaliado por seu custo de produção, e o saldo da conta vinculada tenderá a zero, mesmo porque, se sobrar recursos incentivados, o excedente deverá ser restituído aos cofres públicos, como quitação parcial da obrigação assumida.

Finalmente, quando o filme estiver pronto e a prestação de contas aprovada pelos órgãos competentes, o montante captado que estiver contabilizado no passivo deverá ser cotejado com o custo de produção contabilizado em estoque, mantendo o filme registrado pelo valor suportado com recursos próprios da produtora.

\section{Amortização dos gastos de produção}

A mensuração da amortização dos custos de produção depende, primordialmente, do histórico da produtora.

Em se tratando de uma produtora tradicional, cujos filmes por ela produzidos apresentem pequena variação de desempenho (medida pela receita de bilheteria no cinema nacional), os custos capitalizados de cada filme devem ser amortizados à medida que a produtora for auferindo receita com o filme, sendo feito o controle do desempenho do filme em cada janela de distribuição, ou seja, na mesma razão em que as receitas estimadas para cada mercado forem sendo, efetivamente, auferidas. A taxa de amortização, utilizada para se calcular o valor da realização contábil de um filme em determinado período em determinada janela, deve ser calculada da seguinte forma: o quociente entre a receita auferida em determinada janela no período analisado e a receita total remanescente que ainda se espera auferir naquela janela (isto é, o denominador é representado pela receita que se espera auferir em determinado mercado, sendo o tempo de vida útil original limitado a, no máximo, dez anos, em face das incertezas inerentes à economia brasileira).

No caso de uma produtora com menos experiência, cujos filmes apresentem média variação de desempenho (medida pela receita de bilheteria no cinema nacional), os custos capitalizados de cada filme devem ser amortizados pelo individual-filmforecast-computation-method, ou seja, na mesma razão em que as receitas estimadas forem sendo efetivamente auferidas. A taxa de amortização, utilizada para se calcular o valor da realização contábil de um filme em determinado período, deve ser calculada da seguinte forma: o quociente entre a receita auferida no período analisado e a receita total remanescente que ainda se espera auferir (isto é, o denominador é representado pela receita que ainda se espera auferir no prazo máximo de dez anos, independente da janela de comercialização). Esta taxa deve ser aplicada sobre o custo de produção não amortizado (ou valor contábil de produção líquido). Considerando a dificuldade de fazer projeções de receita com maior precisão, esta sistemática é a mais adequada.

Para uma produtora com pouquíssima experiência e com grande variação de desempenho (medida pela receita de bilheteria no cinema nacional), o ativo deve ser baixado assim que as receitas de comercialização forem sendo auferidas, apurandose resultado nulo, enquanto o filme não tiver sido totalmente baixado. Essa forma é a mais prudente, considerando um ambiente caracterizado por incertezas.

Finalmente, é adotado o critério de manter o filme registrado pelo valor simbólico de um real, que é imaterial e serve para manter o acervo da produtora registrado sem necessitar de controles 
extracontábeis, e transferir este valor simbólico do ativo circulante (estoque de filme) para o ativo realizável a longo prazo (também, estoque de filme). Afinal, não se espera auferir receita com o mesmo num curto período de tempo.

A importância dada à amortização dos custos de produção e a preferência pelo método que considera o desempenho alcançado pelo filme em cada mercado, justifica-se pela observância do Princípio da Competência e por melhor representar o desempenho da produtora. Afinal, se o business-plan for bem elaborado e a amortização corretamente contabilizada, o balanço patrimonial e as notas explicativas demonstrarão, em conjunto, a capacidade de geração de riqueza do ativo da produtora.

Podemos identificar, ainda, como vantagens do método adotado pela produtora tradicional, em relação às mais simples, o fato de observar o Postulado da Continuidade e a convenção da Consistência. O fato de obrigar a elaboração de projeções orçamentárias analíticas propicia a geração de melhores informações para o processo decisório. Afinal, o orçamento e a posterior análise das variações "forçam" a produtora a estudar os mercados nos quais o filme será comercializado, podendo fazer com que o projeto de produção seja adaptado e as técnicas de comercialização aprimoradas.

\section{Evidenciação}

Informações relevantes não contempladas na demonstração do resultado do exercício, no balanço patrimonial nem nas demais demonstrações contábeis devem ser evidenciadas em notas explicativas.

Como proposta, é apresentado a seguir um rol de informações mínimas que, em termos ideais, deveriam ser divulgadas pelas produtoras de forma a permitir ao usuário das demonstrações contábeis melhor interpretá-las.

Nesse sentido, as notas explicativas deveriam conter, no mínimo:

- o business-plan elaborado para cada filme;

- os critérios adotados na elaboração do business-plan;

- as premissas utilizadas para desenvolver o business-plan;
- demonstrações do fluxo de caixa efetivamente gerado pelos filmes individualmente identificados;

- demonstração do fluxo de caixa efetivamente gerado pela produtora;

- o critério de amortização dos custos de produção;

- as janelas em que cada filme já foi exibido e as perspectivas de comercialização futura;

- a política de financiamento dos projetos em andamento;

- o prazo para finalização de projetos já iniciados; e

- o montante de recursos das perdas correspondentes aos projetos abandonados e as respectivas causas.

\section{Exemplo}

Entendendo ser o critério ideal aquele que amortiza os custos de produção em função do desempenho alcançado pelo filme, mercado a mercado, passamos a apresentar o seguinte exemplo para ilustrar como funciona o reconhecimento da receita e a amortização dos custos de produção por esse critério.

A produtora $\mathrm{F} \& \mathrm{R}$, em setembro de $20 \times 1$, acaba a produção do filme Colação, Provas e Defesa, tendo apurado o gasto total de $\$ 500.000$.

Mediante elaboração do business-plan, a F\&R estima auferir $\$ 1.250 .000$ com o filme, sendo $80 \%$ nas salas de exibição no mercado nacional e o restante nas demais janelas de comercialização.

No trimestre outubro/dezembro de 20X1, o filme foi exibido exclusivamente em salas de cinema nacional e a F\&R auferiu receita no valor de $\$ 700.000$.

Considerando que a F\&R é uma produtora tradicional, a amortização do trimestre outubro/dezembro de 20X1 é calculada da seguinte forma:

a) Valor da receita estimada relativamente a salas de exibição no mercado nacional: $\$ 1.250 .000 \times 80 \%=\$ 1.000 .000$;

b) Valor a ser amortizado relativo a salas de exibição no mercado nacional: $\$ 500.000 \times 80 \%=$ $\$ 400.000$;

c) Cálculo da taxa de amortização: 700.000 / $1.000 .000=70 \%$; e

d) Cálculo do valor da amortização: $400.000 \mathrm{x}$ $70 \%=\$ 280.000$. 
Tabela 2 - Resultado do trimestre outubro/dezembro de 20X1

Demonstração de Resultado - Out.-Dez./X1

\begin{tabular}{lc}
\hline Itens \Modelos & Proposto \\
\hline Receita Comercial & 700.000 \\
Despesa Amortização & $(280.000)$ \\
Lucro & 420.000 \\
\hline \hline
\end{tabular}

Fonte: 0 autor.

No trimestre janeiro/março de 20X2, o filme continuou sendo exibido exclusivamente em salas de cinema nacional e a F\&R auferiu receita no valor de $\$ 300.000$.

Amortização do trimestre janeiro/março de 20X2 é calculada da seguinte forma:

a) Valor da receita que ainda se espera auferir nas salas de exibição no mercado nacional: $\$ 1.250 .000$ x 80\% - $700.000=\$ 300.000$;

b) Valor a ser amortizado relativo a salas de exibição no mercado nacional: $\$ 500.000 \times 80 \%-$ $280.000=\$ 120.000$;

c) Cálculo da taxa de amortização: 300.000 / $(1.000 .000-700.000)=100 \%$; e

d) Cálculo do valor da amortização: 120.000 x $100 \%=\$ 120.000$.

Tabela 3 - Resultado do trimestre janeiro/março de 20X2

\begin{tabular}{lc}
\hline Demonstração de Resultado - Jan.-Mar./X2 \\
\hline Itens $\backslash$ Modelos & Proposto \\
Receita Comercial & 300.000 \\
Despesa Amortização & $(120.000)$ \\
Lucro & 180.000 \\
\hline \hline
\end{tabular}

Fonte: o autor.

\section{CONCLUSÃO}

O modelo proposto foi desenvolvido, buscandose aprimorar as práticas das produtoras observando os princípios contábeis, sendo uma de suas características mais importantes a observância dos Princípios Generalizadamente Aceitos no Brasil.

Os modelos brasileiros estudados e atualmente adotados não estão seguindo esses princípios.

Os modelos internacionais estudados não contemplam aspectos importantes existentes na atividade cinematográfica brasileira, principalmente em função dos incentivos fiscais.
Dessa forma, o modelo proposto pode aprimorar a capacidade informativa das produtoras brasileiras, propiciando a geração de informações uniformes e mais confiáveis.

Sob essa ótica, o modelo proposto tem condições de ser adotado pelas produtoras audiovisuais brasileiras e, nesse caso, auxiliaria os produtores a captar recursos, posto que a escassez de orçamentos se configura como um dos maiores limitadores concorrenciais da indústria nacional frente à norte americana.

Mediante essa comparabilidade a sociedade meIhor conheceria a atividade cinematográfica podendo se interessar a financiar o setor através da captação de poupança quer na modalidade de empréstimos, percebendo remuneração pré-fixada; quer integralizando quotas de projetos de produção sob a forma de participação nos lucros, portanto, sem utilizar recursos públicos; além do que, o Governo poderia reduzir as barreiras à concessão de fomento e aumentar os recursos destinados aos mesmos.

A necessidade e o interesse pela padronização das normas contábeis tende a aumentar com a regulação do mercado culminada com a criação da Agência Nacional do Cinema - ANCINE, por força da Medida Provisória $n^{\circ} 2.219$, de 4 de setembro de 2001, alterada pela Medida Provisória n ${ }^{\circ}$ 2.228-1, de 6 de setembro de 2001. Afinal, a contabilidade, se bem aplicada, pode ser entendida como um fundamental banco de dados para a atividade de um órgão regulador, ao permitir entre outras coisas, a comparabilidade das informações contábeis.

Embora a Medida Provisória tenha sido regulamentada pelo Decreto $n^{\circ} 4.456$, de 5 de novembro de 2002, não foi feita qualquer menção à informação contábil, tão somente à prestação de contas dos recursos incentivados. Considerando-se os objetivos da ANCINE (art. $6^{\circ}$, inc. IV) e a criação dos Fundos de Financiamento da Indústria Cinematográfica Nacional - FUNCINES (art. 43, inc. III), conclui-se que é possível a regulação de aspectos contábeis, por parte da Agência, mediante a emissão de pronunciamentos e normas contábeis a serem adotadas pelas entidades que compõem a indústria cinematográfica. Desse modo, caberia à Agência exigir que as entidades publiquem suas demonstrações contábeis, buscando-se com isso reduzir a assimetria informacional, uma vez que se trata de empresas intensivamente financiadas com recursos públicos a fundo perdido. 


\section{REFERÊNCIAS BIBLIOGRÁFICAS}

BRASIL, Presidência da República. Medida Provisória $\mathrm{n}^{\circ} 2.228,6$ de setembro de 2001 . Estabelece princípios gerais da Política Nacional do Cinema, cria o Conselho Superior do Cinema e a Agência Nacional do Cinema - ANCINE, institui o Programa de Apoio ao Desenvolvimento do Cinema Nacional - PRODECINE, autoriza a criação de Fundos de Financiamento da Indústria Cinematográfica Nacional - FUNCINES, altera a legislação sobre a Contribuição para o Desenvolvimento da Indústria Cinematográfica Nacional e dá outras providências. Diário Oficial da União de 5 de setembro de 2001.

BRASIL, Presidência da República. Decreto no 4.456, de 4 de novembro de 2002. Regulamenta o art. 67 da Medida Provisória no 2.228-1, de 6 de setembro de 2001, estabelecendo as competências do Ministério da Cultura e da Agência Nacional do Cinema - ANCINE, com relação aos projetos audiovisuais realizados com base na Lei no 8.313, de 23 de dezembro de 1991, dispõe sobre a transferência de atividades, nos termos do art. 66, inciso I, da referida Medida Provisória, e dos processos relativos aos projetos audiovisuais realizados com base na citada Lei no 8.313, de 1991, e na Lei no 8.685, de 20 de julho de 1993, e dá outras providências.

CARDOSO, Ricardo Lopes. Apuração do resultado contábil de uma produtora cinematográfica: uma contribuição ao aprimoramento da informação contábil. 2001 .
Dissertação (Mestrado em Ciências Contábeis) - Universidade do Estado do Rio de Janeiro, Rio de Janeiro.

CONES, Jonh W. 43 ways to finance your feature film: a comprehensive analysis of film finance. Illinois: Southern Illinois University, 1998.

DANIELS, LEEDY, SILLS. Movie money: understanding Hollywood's (creative) accounting practices. Los Angeles: Silman-James, 1998.

HENDRIKSEN, Eldon S.; VAN BREDA, Michael F. Teoria da Contabilidade. Tradução de Antonio Zoratto Sanvicente. São Paulo: Atlas, 1999.

IUDÍCIBUS, Sérgio de. Teoria da Contabilidade. 5.ed. São Paulo: Atlas, 1997.

FIPECAFI. Manual de contabilidade das sociedades por ações: aplicável às demais sociedades. 5.ed. São Paulo: Atlas, 2000.

KIESO, D. WEYGANDT, J. Intermediate Accounting. 8.ed. Nova lorque: John Wiley \& Sons, 1995.

MINISTÉRIO DA CULTURA. A economia do cinema no Brasil. Brasília: Secretaria para o Desenvolvimento do Audiovisual - MinC.[19-].

MOORE, Shuyler M. The biz: the basic business, legal and financial aspects of the film industry. Los Angeles: Silman-James, 2000. 